\title{
Prognostic and predictive role of CXCR4, IGF-1R and Ezrin expression in localized synovial sarcoma: is chemotaxis important to tumor response?
}

\author{
Emanuela Palmerini ${ }^{1 * \dagger}$, Maria Serena Benassi ${ }^{2+}$, Irene Quattrini ${ }^{2}$, Laura Pazzaglia ${ }^{2}$, Davide Donati ${ }^{3}$, Stefania Benini ${ }^{4}$,
} Gabriella Gamberi ${ }^{4,6}$, Marco Gambarotti ${ }^{4}$, Piero Picci ${ }^{2}$ and Stefano Ferrari ${ }^{5}$

\begin{abstract}
Background: Synovial sarcoma (SS) is a rare tumor, with dismal survival when metastatic. The role of adjuvant chemotherapy is debated. New prognostic and predictive factors are needed.

Methods: We reviewed patients with localized SS; SS18-SSX fusion transcript presence was confirmed by FISH and RT-PCR. Expression of CXCR4, IGF-1R and Ezrin were evaluated by immunohistochemistry.

Results: Tumor samples from 88 SS patients (45 female; 43 male) with median age 37 years (range 11-63) were selected. The size of the lesion was $>5 \mathrm{~cm}$ in $68 \%$ of patients and $34 \%$ of cases presented biphasic histotype. All patients underwent surgery, 56\% adjuvant radiotherapy (RT), 65\% adjuvant chemotherapy. A positive stain for IGF-1R was detected in 55 patients, with nucleus expression in 21 patients. CXCR4 was expressed in 74 patients, nuclear pattern in 31 patients. 80 SS were positive to Ezrin, 48 had cytoplasmatic location, 32 membrane location. With a median follow-up of 6 years (1-30 years), the 5-year overall survival (OS) was $70 \%$ (95\% Cl 60-81). 5-year OS was 63\% (95\% Cl 41-85\%) for patients with positive IGF-1R/nuclear expression, and 73\% (95\% Cl 61-85\%; $P=0.05)$ in negative patients. 5-year OS was 47\% (95\% Cl 27-66\%) in patients with positive CXCR4/nuclear staining, and 86\% (95\% Cl 76-96\%, $P=0.0003$ in negative cases. No survival difference was found according to Ezrin expression. By multivariate analysis, nuclear expression of CXCR4 and IGF-1R was confirmed independent adverse prognostic factor for SS patient survival linked to the use of chemotherapy.

Conclusions: Our findings have important potential implications demonstrating that together with clinical prognostic factors such as radiotherapy and age, CXCR4 and IGF-1R negatively influences survival in patients with localized SS. We believe that further studies addressed to the effects of CXCR4 and IGF-1R inhibitors on cell viability and function are needed to plan new and more appropriate SS treatments.
\end{abstract}

Keywords: CXCR4, IGFR1, Ezrin, Synovial sarcoma, Prognostic factors, Predictive factors

\section{Background}

Synovial sarcoma (SS) comprises approximately $8 \%$ of all soft tissue sarcomas (STSs), with the lower limbs being the most common site of primary disease [1]. Although relatively rare, SS is the third most common extremity STS. It affects mostly young adults, with a median age of 35 years [2]. Three histologic subtypes of SS are described:

\footnotetext{
* Correspondence: emanuela.palmerini@ior.it

${ }^{\dagger}$ Equal contributors

'PROMETEO Laboratory/Section of Chemotherapy, Research, Innovation \& Technology (RIT) Department, Istituto Ortopedico Rizzoli, Via Pupilli, 1, 40136, Bologna, Italy

Full list of author information is available at the end of the article
}

monophasic, entirely composed of spindle cells; biphasic, composed of both spindle cells and epithelial cells; and poorly differentiated subtypes [3]. Synovial sarcoma contains a characteristic translocation $(\mathrm{X} ; 18)(\mathrm{p} 11 ; \mathrm{q} 11)$, representing the fusion of $S Y T$ on chromosome 18 with either SSX1, SSX2, or rarely SSX4 on chromosome X [4]. The resulting fusion genes appear to be mutually exclusive and concordant in primary and metastatic tumors [5]. In a previous series of 250 patients with SS dating back to 1976, we demonstrated that stage, size, age, and histologic subtype were independent factors for event free survival [6]. Also, this study provided further evidence that adjuvant 
radiotherapy is a significant independent prognostic factor, and should always be performed in large lesions [7]. Other factors, such as surgical margins, p53 overexpression, Ki-67 proliferative index, and SYT-SSX fusion type, have been identified [8-13]. The role of adjuvant chemotherapy in SS is debated. In the metastatic setting, a high response rate to ifosfamide-based therapy has been reported (40\%$70 \%)[14,15]$. Therefore, adjuvant chemotherapy is frequently used for localized disease $[1,16]$. A previous genetic study [17] identified a hypoxia-induced metastatic profile in pleomorphic high-grade STSs providing information for selection of high-risk tumors. Multiple regulators of signalling pathways including EGF and FGF receptors, members of the Hedgehog (Hh) family, genes involved in retinoic and Notch pathways, and in chromatin remodelling were found up regulated in SS [18].

Chemokine receptor 4 (CXCR4) is a seven-transmembrane $\mathrm{G}$ protein-coupled chemokine receptor and it is the chemokine receptor most commonly expressed in tumor cells, with increased expression in presence of metastatic disease in many tumors including bone and soft tissue sarcomas $[19,20]$. CXCR4 has also been demonstrated to be involved in cell migration and invasion, as well as angiogenesis.

Insulin growth factor-1 receptor (IGF-1R) is involved in IGF-II signalling and down-regulation or inhibition of this receptor leads to increased numbers of apoptotic cells in SS18-SSX-transformed cells and SS cell lines [21]. In addition, a study that investigated IGF-1R expression in 35 SS found that there was an association between IGF-1R expression and an increased incidence in lung metastasis [22].

Ezrin is a membrane-cytoskeleton linker protein involved in growth regulating and metastatic behaviour of cancer cells. Our previous experience in osteosarcoma detected Ezrin immunoreactivity in the majority of patients with non-metastatic osteosarcoma of the extremity and revealed that the cytoplasmatic pattern was associated with good prognosis [23].

In order to identify a subgroup of patients with poorer prognosis who most likely benefit from adjuvant chemotherapy, we selected localized chemo-naïve SS patients from our previously studied series [6] and assessed the prognostic role of CXCR4, IGF-1R and Ezrin by correlating their expression with clinical and histological parameters.

\section{Methods}

\section{Design and patients}

This study is a systematic mono institutional retrospective analysis. From the previous series of 250 patients [6] referred to our Institute between 1976-2008, we selected patients admitted for first diagnosis; therefore, metastatic and recurrent patients at presentation were excluded. All patients with incomplete clinical and follow-up data were also excluded. General informed consent to the use of material was obtained from all adult patients or from parents/guardians for minors from 2004.

The research protocol was approved by the ethics committee of the Rizzoli Orthopedic Institute.

\section{Data collection}

Demographic data (age at onset, gender, follow-up duration), clinical-histological presentation (biphasic, monophasic/poorly differentiated, tumor size, site), treatment (R0/R1 resection, adjuvant chemotherapy, adjuvant radiotherapy), and outcome (overall survival (OS), were collected. Follow-up was obtained from hospital charts, or if necessary, by a phone call.

\section{Histology and molecular studies}

The diagnosis was confirmed by pathologists with expertise in soft tissue and bone tumors, after revision of histological slides according to histopathological and immunohistochemical criteria [3]. The presence of SS18 (SYT) gene rearrangement and fusion transcripts was assessed by Fluorescence in situ hybridization (FISH) and Reverse Transcriptase-Polymerase Chain Reaction (RT-PCR) analysis for diagnosis confirmation.

\section{FISH analysis}

FISH was performed using the SS18(SYT) (18q11.2) VYsis LSI Dual Color Break-apart DNA probes (Abbott Molecular, Des Plaines, IL, USA) according to the manufacturer's protocol. A minimum of 100 tumor cell nuclei with intact morphology as determined by DAPI counterstaining were counted in the previously marked neoplastic area. A positive result was defined as the presence of a visible translocation (separation of red and green signals $>3$ signal diameters) in more than $10 \%$ of the cells [24].

\section{RT-PCR analysis}

RNA was extracted from fresh tissue using a modified method including Trizol Reagent (Invitrogen, Carlsbad, $\mathrm{CA}$ ) and the column of RNeasy Mini Kit (Qiagen GmbH, Hilden Germany). $2 \mu \mathrm{g}$ of RNA was reverse transcribed using High Capacity cDNA Archive Kit (Applied Biosystems, Foster City, CA). The primers used for detection of $\mathrm{t}(\mathrm{X}$;18) SS18(SYT)-SSX1 and $\mathrm{t}(\mathrm{X} ; 18) \mathrm{SS} 18$ (SYT)-SSX2 by PCR amplification was: forward SS18 5'GGA CAA GGT CAG CAG TAT GGA3'; reverse primers for SSX1 5'TTG GGT CCA GAT CTC TTA TT3'; and reverse for SSX2 5' 'TTGGGTCCAGATCTCTCGTG3' [25].

\section{Immunohistochemistry staining}

Paraffin embedded tissue from non-treated patients was used for immunohistochemistry (IHC) analysis. The sections $(4 \mu \mathrm{m}$ thickness) were de-paraffinized by $30 \mathrm{mi}-$ nutes in dry oven at $55-60^{\circ} \mathrm{C}$ and 1 hour in xylene; then 
the slides were rehydrated in graded alcohol 100\%, 95\%, $75 \%$. After rinsing with water for 2 minutes, sections were pre-treated with $3 \%$ hydrogen peroxide for $5 \mathrm{mi}$ nutes and Universal Block (KPL, Inc.) for 15 minutes. The sections were incubated for 30 minutes at room temperature with monoclonal antibodies CXCR4 (Ab2074, Abcam, Cambridge, UK; 1:1000 dilution), IGF-1R (C-20 Santa Cruz Biotechnology, Inc. CA, USA; 1:100 dilution), Ezrin (ThermoScientific, Fremont, CA, USA; 1:200 dilution).

Antibody detection was performed using UltraView Universal DAB Detection Kit and UltraView Universal Alkaline Phosphatase Red Detection Kit (Ventana Medical Systems, Tucson AZ, USA). Pre-treatment for antigen retrieval was performed at $95^{\circ} \mathrm{C}$ with Tris-EDTA ph 8 for 20 minutes. Sections were counterstained with haematoxylin, dehydrated and mounted.

The negative control was prepared omitting the primary antibody. Positive controls included in each run were HELA for CXCR4 and human kidney for IGF-1R and Ezrin.

The immunoreactivity was interpreted by the percentage of positive cells $(0=$ negative, $1=<25 \%$ of cells, $2=$ $26-75 \%$ of cells, $3=$ positivity of $>75 \%$ of cells). All samples scored 1 to 3 were considered positive. Cytoplasmatic, nuclear and membrane immunoreactivity was considered for the staining distribution pattern.

\section{Statistical analysis}

The following parameters were examined for statistical prognostic correlations: patient age, tumor size, surgical margins, histology, use of chemotherapy, use of radiotherapy, total expression of CXCR4, nuclear and/or membrane/cytoplasm expression; total expression of IGFR1, nuclear and/or cytoplasmatic expression. Total expression of Ezrin, cytoplasmatic only and cytoplasmatic/membrane expression. The following categories were compared: patients age (adolescent and young adults (AYA) with < 30 years versus adults with $\geq 30$ years); tumor size $(\leq 5 \mathrm{~cm}$ versus $>5 \mathrm{~cm}$ ); surgical margins (adequate including wide or radical versus inadequate including intralesional, marginal or contaminated margins, according to Enneking's classification) [26]; histology (biphasic versus other histotypes); adjuvant treatments (chemotherapy or radiotherapy performed within 3 months after tumor excision). Chi-square $\left(x^{2}\right)$ test with Fisher's exact $p$ value was used to correlate protein expression with clinical parameters. Overall survival (OS) time was calculated from the time of admission at our Institute to death or last follow-up visit. All time-to-event end points were modelled using the method of Kaplan and Meier and analysed by the log-rank test. The results of the Cox model analysis were reported as relative risks (RRs) and 95\% confidence intervals (CIs).

\section{Results}

A total of 88 consecutive patients were selected. Fortyfive were female and 43 male; median age was 37 years (range 11-63); 14 were adolescents and young adults (AYA) ( $<30$ years) and 74 were adults ( $\geq 30$ years). Size of the lesion was $>5 \mathrm{~cm}$ in 60 patients $(68 \%), \leq 5 \mathrm{~cm}$ in $24(27 \%)$ and unknown in 4 patients. The tumor site was trunk in 13 cases (15\%), lower extremity in 64 cases (73\%), upper extremity in 11 cases (12\%). Concerning histotypes, 30 patients (34\%) had biphasic SS, 51 (58\%) monophasic SS and 7 (8\%) poorly differentiated SS. All patients underwent surgery with adequate surgical margins in 68 cases, inadequate in 18 and in 2 cases surgical margins were unknown. Amputation was performed in 24 patients (27\%). Forty-seven patients $(53 \%)$ underwent adjuvant radiotherapy (RT) and 57 (65\%) chemotherapy, 27 of them (47\%) preoperatively (epirubicin/adrymicin and ifosfamide combination in 49 cases, non-ifosfamide containing regimen in 8 cases and in 1 case the treatment was unknown).

\section{FISH and RT-PCR Analysis}

By FISH analysis, all 88 SS presented SS18 (SYT) gene rearrangement resulting in $(\mathrm{X} ; 18)(\mathrm{p} 11.2 ; \mathrm{q} 11.2)$ translocation, thus confirming the histological diagnosis. The presence of SSX fusion transcripts was assessed on 46 frozen tissues by RT-PCR: 28 cases presented SSX1 variant, 18 had SSX2 variant.

\section{Immunohistochemistry}

CXCR4 was positive in 74 SS (84\%), 43 had a membrane/cytoplasmatic staining, 31 nuclear (7 nuclear only and 24 nuclear and cytoplasmatic) (Figure 1a,b).

A positive expression for IGF-1R was detected in 55 patients (62.5\%), 34 had a membrane/cytoplasmatic staining, 21 presented nuclear positivity (5 nuclear only and 16 both nuclear and cytoplasmatic) (Figure 1c,d). No significant difference was observed for CXCR4 and IGF-1R proteins expression between biphasic and monophasic SS in terms of positivity [CXCR4: biphasic: 25/30 (83\%); monophasic: 44/51 (86\%); IGF-1R: biphasic: 17/30 (57\%); monophasic: $33 / 51(64 \%)$ ], and intracellular distribution [nuclear CXCR4: biphasic: 8/30 (27\%); monophasic: 21/51 (41\%); IGF-1R: biphasic: 6/30 (20\%); monophasic: 14/51 (27\%)].

Nuclear expression of both CXCR4 and IGF-1R was detected in 8 cases.

80 SS were positive to Ezrin (91\%), 48 presented only cytoplasmatic location while 32 had cytoplasmatic and/ or membrane staining. Interestingly, the percentage of positive cases in biphasic was higher than in monophasic subgroup ( $100 \%$ vs. $86 \%$, exact Fisher's test $P=0.04)$. Concerning intracellular staining distribution, while biphasic had exclusively Ezrin cytoplasmatic location in 


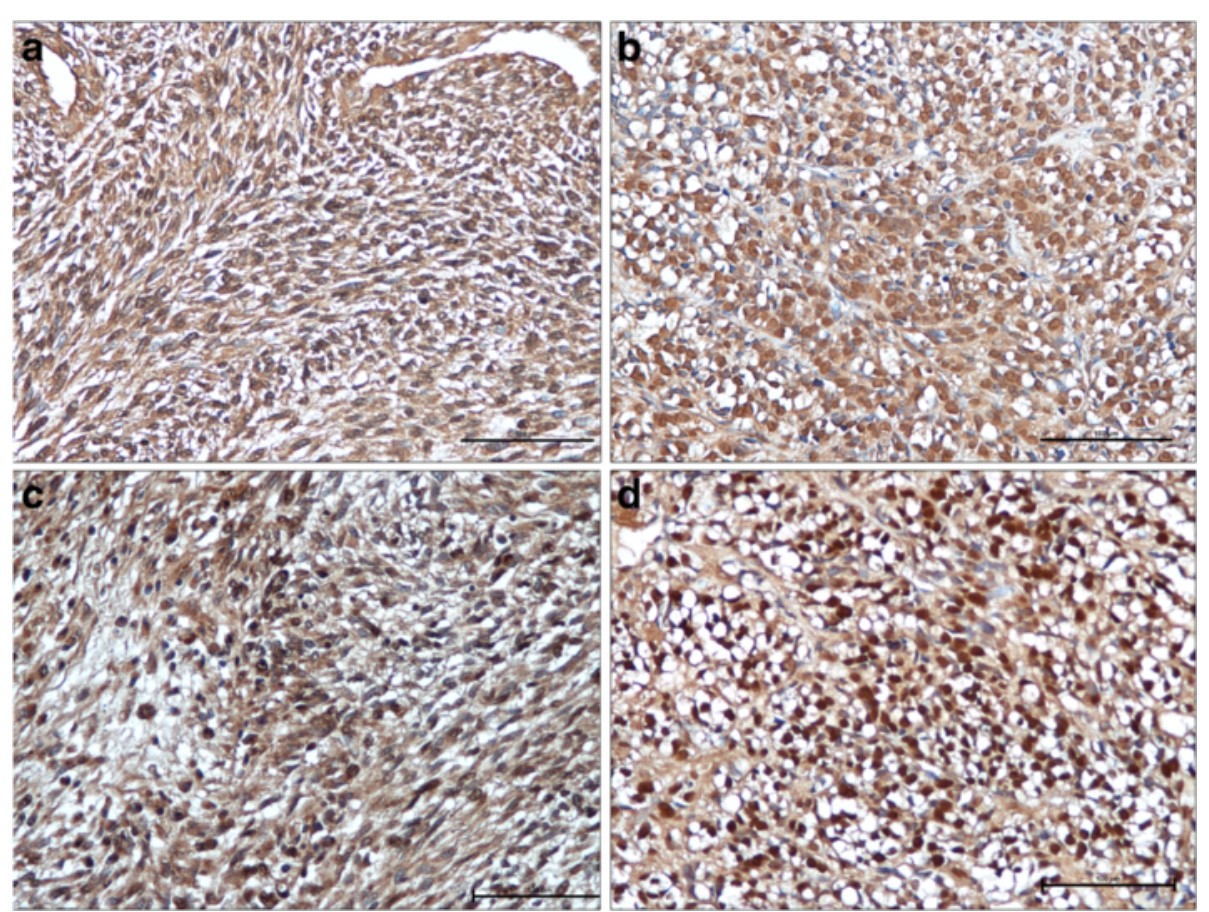

Figure 1 Expression of CXCR4 and IGF-1R in synovial sarcoma. Immunohistochemical expression of CXCR4 with cytoplasmatic (a) and nuclear (b) distribution. Immunohistochemical expression of IGF-1R with cytoplasmatic (c), and nuclear distribution (d) (IHC 20X).

about half of cases $(16 / 30 ; 53 \%)$ and combined cytoplasmatic/membrane expression in 14/30 (47\%), the distribution pattern of monophasic SS was predominantly cytoplasmatic. In detail, $32 / 44$ cases $(73 \%)$ had only cytoplasmatic staining, 12/44 (27\%) had both cytoplasmatic and membrane positivity and 6 cases had localized membrane reactivity.

\section{Outcome and statistical correlations}

With a median follow-up of 6 years (1-30 years), the 5year overall survival (OS) was $70 \%(95 \% \mathrm{Cl} 60-81 \%)$. The 5 -year OS was significantly better for young patients (100\% for AYA and $65 \%$ for adult patients, $P=0.003$ ).

For CXCR4 and IGF-1R expression and outcome correlation, the positivity in the nucleus was chosen and defined as CXCR4/nuclear staining and IGF-1R/nuclear expression.

The 5-year OS was significantly better for patients with negative CXCR4/nuclear staining (86\% for negative and $47 \%$ for positive patients, $P=0.0003$ ) (Figure $2 \mathrm{~d}$ ), and for patients with negative IGF-1R/nuclear expression $(73 \%$ for negative and $63 \%$ for positive patients, $P=$ 0.05) (Figure 2a). According, combined CXCR4/IGF-1R/ nuclear positive staining (double positive) was associated with poorer survival (double positive: 5-year and 8-year OS 57\% (\% CI 20-94) and 20\% (\% CI 0-52); non- double positive: 5-year and 8-year OS 71 (\% CI 60-83) and 67\% (\% CI 55-73); $P=0.02$ ).
No significant correlation between Ezrin expression and clinical variables was found (Table 1).

An increased overall survival, close to statistical significance $(p=0.07)$, was documented in patients undergoing radiation therapy, while chemotherapy, surgical margins, histologic subtype (biphasic vs. other) as well as Ezrin expression did not have any impact on the outcome (Table 1).

Furthermore, in 46 patients with frozen tissues available we found no difference between SSX variants. The 5 -year OS was 74\% (\% CI 56-92) for SSX1, and 68\% (\% CI 42-94; $\mathrm{p}=0.8$ ) for SSX2.

Finally, we performed a survival analysis in 2 subgroups of patients: chemotherapy treated and untreated patients. In the first group the 5-year OS was $75 \%$ for patients with IGF1R/nuclear negative staining versus $66 \%$ for positive patients $(\mathrm{p}=0.9)$ and $90 \%$ for patients with CXCR4/nuclear negative staining versus $32 \%$ for positive patients $(\mathrm{p}=0.0001)$ (Figure $2 \mathrm{~b}, \mathrm{e})$. In the group of untreated patients, the 5 -year OS was and $85 \%$ for patients with IGF1R/nuclear negative staining versus $43 \%$ for positive patients $(P=0.01)$ and $78 \%$ for patients with CXCR4/nuclear negative staining versus $65 \%$ for positive patients $(P=0.5)$ (Figure $2 \mathrm{c}, \mathrm{f})$. After multivariate analysis nuclear expression of CXCR4, IGF-1R and use of RT were confirmed statistically significant independent factors for OS, while and age were not (Table 2). 


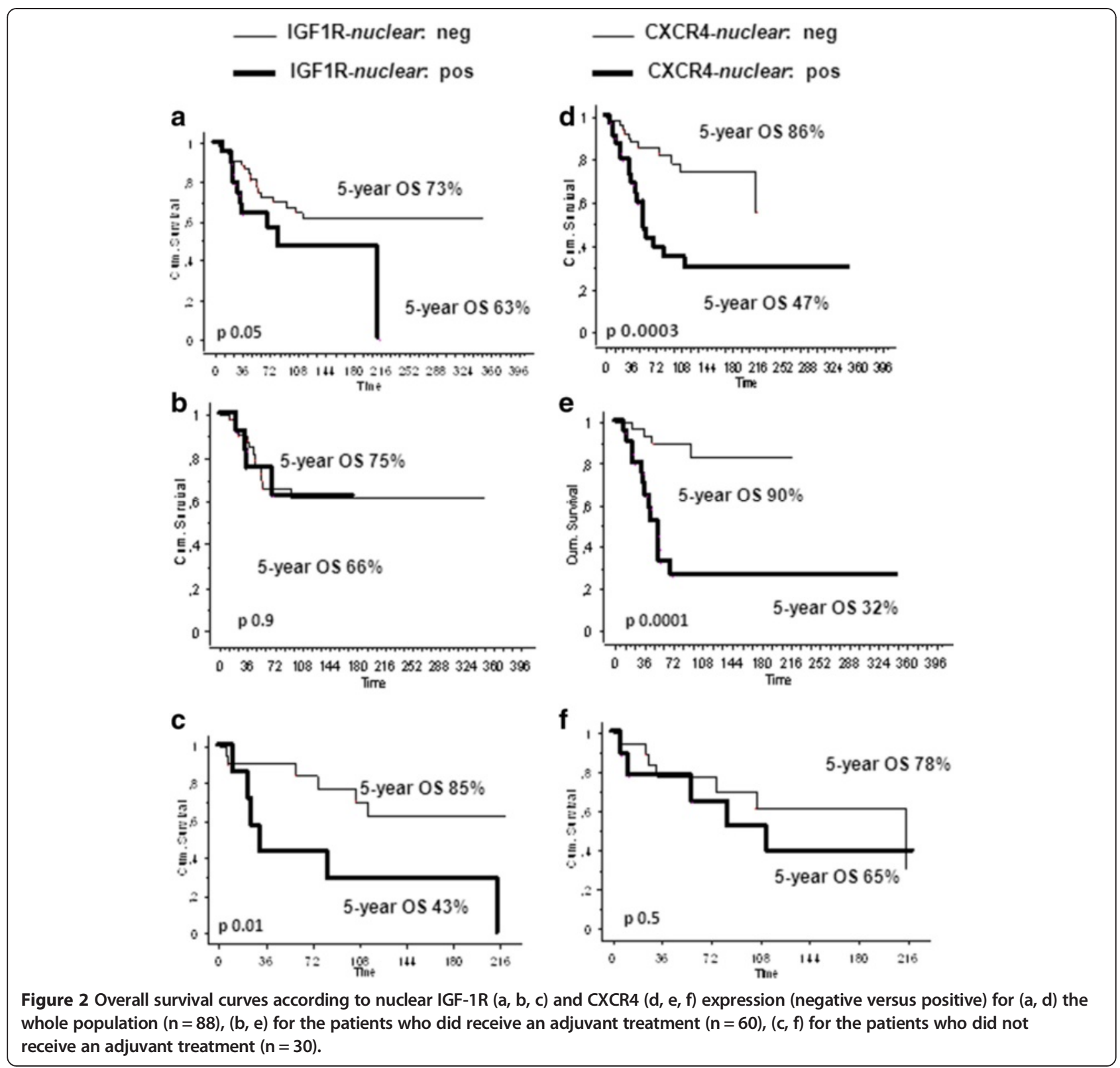

\section{Discussion}

As for other high-grade malignant soft tissue tumors, the standard treatment of SS is the wide surgical removal of the lesion and radiotherapy [7]. Survival rate ranges from $62 \%$ to $83 \%$ in a variety of studies and better results are reported for smaller tumors $(<5 \mathrm{~cm})$, and for those in which negative surgical margins are achieved $[6,16]$.

The role of adjuvant chemotherapy in SS remains controversial and definitive conclusions have been difficult to make in absence of histology-specific chemotherapy protocols. Nonetheless adjuvant chemotherapy has been employed in case of localized disease, especially in the pediatric population [12]. With the currently available treatments, in particular in adults and for advanced/ recurrent disease [15,27], the prognosis of SS remains unsatisfactory and there is an urgent need to identify prognostic and predictive factors.

Our SS population is representative of the largest previously published SS series $[6,12]$ for clinical and treatment characteristics and, most importantly, for expression of prognostic factors for overall survival. This study includes a consecutive series of localized SS patients, treated in a referral center. In all cases the diagnosis of SS was confirmed by the presence of $(\mathrm{X} ; 18)$ (p11.2;q11.2) translocation [13] and the possible prognostic role of IGF-1R, CXCR4 and Ezrin was assessed by correlating protein immunoreactivity with clinical and histological features. 
Table 1 Univariate analysis for 5-year OS

\begin{tabular}{|c|c|c|c|c|c|}
\hline Variable & & $\begin{array}{l}\text { Patient } \\
\mathrm{N}^{\circ}(88)\end{array}$ & $\begin{array}{l}5 \text {-year } \\
\text { OS (\%) }\end{array}$ & $\begin{array}{l}95 \% \\
\mathrm{Cl} \\
\end{array}$ & $p$ \\
\hline \multirow[t]{2}{*}{ Age } & Adult & 74 & 65 & $53-77$ & 0.003 \\
\hline & AYA & 14 & 100 & & \\
\hline Size & $<5 \mathrm{~cm}$ & 24 & 82 & $66-98$ & 0.4 \\
\hline uk in 4 pts & $\geq 5 \mathrm{~cm}$ & 60 & 67 & $53-80$ & \\
\hline \multirow[t]{2}{*}{ Margins $^{\circ}$} & Adequate & 68 & 69 & $57-81$ & 0.8 \\
\hline & Inadequate & 18 & 76 & $51-100$ & \\
\hline \multirow[t]{2}{*}{ Histology } & Biphasic & 30 & 67 & $53-80$ & 0.5 \\
\hline & Other & 58 & 76 & $59-93$ & \\
\hline \multirow[t]{2}{*}{ Chemotherapy } & No & 28 & 73 & $67-85$ & 0.5 \\
\hline & Yes & 60 & 68 & $54-81$ & \\
\hline \multirow[t]{2}{*}{ Radiotherapy* } & No & 37 & 67 & $51-83$ & 0.07 \\
\hline & Yes & 47 & 77 & $63-92$ & \\
\hline \multirow[t]{2}{*}{ IGF-1R } & Negative & 33 & 72 & $53-90$ & 0.3 \\
\hline & Positive & 55 & 69 & $56-82$ & \\
\hline \multirow[t]{2}{*}{ IGF-1R/nuclear } & Negative & 67 & 73 & $61-85$ & 0.05 \\
\hline & Positive & 21 & 63 & $41-85$ & \\
\hline \multirow[t]{2}{*}{ CXCR4 } & Negative & 14 & 92 & $76-100$ & 0.1 \\
\hline & Positive & 74 & 66 & $54-78$ & \\
\hline \multirow[t]{2}{*}{ CXCR4/nuclear } & Negative & 57 & 86 & $76-100$ & 0.0003 \\
\hline & Positive & 31 & 47 & $54-78$ & \\
\hline \multirow[t]{2}{*}{ EZRIN } & Negative & 8 & 100 & & 0.2 \\
\hline & Positive & 80 & 67 & $55-78$ & \\
\hline \multirow{2}{*}{$\begin{array}{l}\text { EZRIN positivity } \\
\text { pattern }\end{array}$} & Cytoplasmatic & 49 & 65 & $50-79$ & 0.9 \\
\hline & Cyto/membrane & 31 & 70 & $52-89$ & \\
\hline
\end{tabular}

AYA: adolescent and young adults; OS: overall survival; IGF-1R: insulin growth factor-1 receptor; CXCR4: chemokine (C-X-C motif) receptor 4; uk:

${ }^{\circ}$ unknown in 2 pts.

*unknown in 4 pts.

Nuclear expression of CXCR4 and IGF-1R resulted a strong independent adverse prognostic factor for overall survival. Interestingly, the meaning of the nuclear expression of the two markers was linked to the use of chemotherapy. In fact, IGF-1R/nuclear expression was significantly related to a poor probability of survival, but only in patients who did not undergo adjuvant chemotherapy. On the contrary, CXCR4/nuclear negative expression was predictive of poor prognosis, but only in patients who received adjuvant chemotherapy.

IGF-1R is a transmembrane receptor highly expressed in many human cancers, including sarcomas [28]. The implication of IGF/IGF-1R axis in SS development and management was discussed in a study demonstrating that SS18-SSX1 or SS18-SSX2 fusion genes up-regulate insulin-like growth factor-2 (IGF-2) through epigenetic mechanisms [29]. Finally, by microarray analysis, high expression levels of the ligand IGF-2 were found in SS
Table 2 Multivariate analysis for 5-year OS

\begin{tabular}{lll}
\hline VARIABLE & & HR for 5-year OS \\
\hline IGF-1R-nuclear & Positive & 1 \\
& Negative & $0.4[0.2-0.9]$ \\
& & $p=0.04$ \\
CXCR4-nuclear & Positive & 1 \\
& Negative & $0.3[0.1-0.7]$ \\
& & $p=0.003$ \\
SIZE & $\leq 5 \mathrm{~cm}$ & 1 \\
& $>5 \mathrm{~cm}$ & $2.6[1-7]$ \\
& & $p=0.06$ \\
RADIOTHERAPY & Yes & 1 \\
& No & $3.8[1.6-9.2]$ \\
AGE & & $p=0.002$ \\
& AYA & 1 \\
& Adult & $6.3[0.8-50.2]$ \\
& & $p=0.08$ \\
\hline
\end{tabular}

HR: hazard ratio; AYA: adolescent and young adults; OS: overall survival; IGF-1R: insulin growth factor-1 receptor; CXCR4: chemokine (C-X-C motif).

samples [30], that also expressed IGF-1R [31]. In this study we demonstrated that a high percentage of SS presented positivity for IGF-1R, with nuclear and/or cytoplasmatic immunostaining in both monophasic and biphasic subtypes. As previously described, IGF-IR auto-regulates IGFIR gene by translocating to nucleus [32].

In our SS, as in breast and lung tumor [32,33], the survival was significantly better for patients with negative IGF-1R/nuclear expression when compared to nuclearpositive patients. Although this result emphasizes the importance of immunostaining location, the poor-prognostic significance of IGF-1R/nuclear expression, also confirmed by multivariate analysis, was limited to a subgroup of patients who did not receive systemic therapy. We believe that this may reinforce the role of IGF-1R as strong prognostic factor in SS, selecting high-risk patients candidates for adjuvant therapy.

Recently, Asmane et al. [34] suggested that the nuclear location of IGF-1R might activate signaling pathways demonstrating that patients with advanced sarcoma had better progression-free and overall survival when treated with IGF-1R antibody therapy.

In the last years there is an increasing interest on the interaction of the cancer cells with their microenvironment, mediated by the chemokine ligand CXCL12, and its chemokine receptor 4 (CXCR4) [35]. This axis plays critical roles in tumor progression, including promotion of tumor cell proliferation and survival, metastasis and angiogenesis [36]. CXCR4 is important for the prognosis of several tumor types, including melanoma [36], colon [37], pancreatic [38], gastric [39] cancer and STS [20]. Our results showed that CXCR4 nuclear expression was 
an independent adverse prognostic factor for localized SS predominantly in the group of patients who received chemotherapy. Accordingly, D' Alterio et al. [40] demonstrated that a high expression of CXCR4 was associated with poor response in metastatic renal cancer patients treated with sunitinib.

Thus, the inferior survival of SS patients with CXCR4 nuclear positivity, as compared with negative patients, might suggest that CXCR4 is involved in mechanisms of resistance to chemotherapy. The anti-tumor activity of a CXCR4 antagonist has been shown in pre-clinical and animal tumor models [41], and several clinical studies on CXCR4 antagonists as chemosensitizer for treatment of patients with hematological and solid tumors are underway [35,42].

The role of Ezrin, a cytoskeleton linker protein that is actively involved in regulating the growth and metastatic capacity of cancer cells, has been reported in adult soft tissue sarcoma with a direct correlation between IHC staining intensity, histological grade and infiltrative growth pattern [43]. In our series the majority of SS were positive to Ezrin revealing that expression and distribution pattern of staining (cytoplasmatic/membraneous) was not as relevant for prognosis as in osteosarcoma [23]. However, all 8 patients with negative Ezrin immunostaining were alive at 5 years.

Altogether, these findings, should be analyzed in the context of older reported prognostic factors such as Ki67 and p53 [44,45], and newer ones such as CINSARC [46]. In a future scenario an high expression of Ki67, a mutated p53, a C2 CINSARC signature (increased genomic complexity), together with nuclear positivity for CXCR4 and IGF-1R expression, could represent novel tools to stratify SS patients for treatment.

\section{Conclusions}

Our findings have important potential implications demonstrating that together with clinical prognostic factors such as radiotherapy and age, CXCR4 and IGF-1R nuclear expression is a strong independent adverse prognostic factor for SS patient survival, linked to the use of chemotherapy. Based on these data, CXCR4/nuclear expression was predictive of poor prognosis in patients who received adjuvant chemotherapy, emphasizing its possible involvement in drug-resistance mechanisms. In contrast, IGF-1R/nuclear expression, significantly related to poor survival in patients who did not receive adjuvant chemotherapy, may differentiate a subgroup of SS patients candidate to adjuvant chemotherapy.

We believe that CXCR4 antagonists, combined with chemotherapy, could act as chemosensitizer in SS, as suggested in other hematological and solid tumors settings [35,42]. Further studies addressing the effects of CXCR4 and IGF-1R inhibitors on cell viability and function are needed to plan new and more appropriate SS treatments.

\section{Competing interests}

The authors state that there is no potential conflict of interest both financial and personal.

All authors have read and approved the contents of this manuscript and declare that the work is original and had not been submitted or published elsewhere.

\section{Authors' contributions}

EP, MSB, SF: substantive intellectual contribution to conception and design of study, drafting and revision of manuscript, statistical analyses and interpretation of data. PP, EP, MSB, SF: final approval of the version to be published. IQ, LP, SB, GG: molecular studies including PCR and FISH, TMA construction and immunohistochemistry; data acquisition and analysis. PP, MG pathology. SF, EP: chemotherapy. DD: surgery. All authors read and approved the final manuscript.

\section{Acknowledgments}

This work was supported by: the Associazione Onlus "il Pensatore: Matteo Amitrano"; 5\% donation (Italy), EU FP7 Eurosarc, Biobanca Oncologia Emilia Romagna.

Dr E. Pamerini's work is supported by the Emilia-Romagna Region HighTechnology Network, PROMETEO Laboratory at Istituto Ortopedico Rizzoli.

\section{Author details}

'PROMETEO Laboratory/Section of Chemotherapy, Research, Innovation \& Technology (RIT) Department, Istituto Ortopedico Rizzoli, Via Pupilli, 1, 40136, Bologna, Italy. 'Laboratory of Experimental Research, Bologna, Italy. ${ }^{3}$ Orthopaedic Surgery, Bologna, Italy. ${ }^{4}$ Surgical Pathology, Bologna, Italy. ${ }^{5}$ Section of Chemotherapy Musculoskeletal Oncology Department, Istituto Ortopedico Rizzoli, Bologna, Italy. ${ }^{6}$ Department of Biomedical and Neuromotor Sciences, University of Bologna, Bologna, Italy.

Received: 25 September 2014 Accepted: 30 December 2014 Published online: 23 January 2015

\section{References}

1. Brennan MF, Singer S, Maki RG, O'Sullivan B. Soft tissue sarcoma. In: DeVita VT, Hellmann S, Rosenberg SA, editors. Cancer Principles and Practice of Oncology. 8th ed. Philadelphia, PA: Lippincott Williams and Wilkins; 2008. p. 1741-94.

2. Eilber FC, Dry SM. Diagnosis and management of synovial sarcoma. J Surg Oncol. 2008:97:314-20.

3. Fletcher CDM, Unni KK, Mertens F. Pathology and genetics of tumors of soft tissue and bone. Lyon, France: IARC Press; 2002.

4. Kawai A, Woodruff J, Healey JH, Brennan MF, Antonescu CR, Ladanyi M. SYT-SSX gene fusion as a determinant of morphology and prognosis in synovial sarcoma. N Engl J Med. 1998:338:153-60.

5. Panagopoulos I, Mertens F, Isaksson M, Limon J, Gustafson P, Skytting B, et al. Clinical impact of molecular and cytogenetic findings in synovial sarcoma. Genes Chromosomes Cancer. 2001;31:362-72.

6. Palmerini E, Staals EL, Alberghini M, Zanella L, Ferrari C, Benassi M, et al. Synovial sarcoma: retrospective analysis of 250 patients treated at a single institution. Cancer. 2009;115(13):2988-98.

7. ESMO/European Sarcoma Network Working Group. Soft tissue and visceral sarcomas: ESMO Clinical Practice Guidelines for diagnosis, treatment and follow-up. Ann Oncol. 2012;23(7):92-9.

8. Lewis JJ, Antonescu CR, Leung DHY, Blumberg D, Healey JH, Woodruff JM, et al. Synovial sarcoma: a multivariate analysis of prognostic factors in 112 patients with primary localized tumors of the extremity. J Clin Oncol. 2000;18:2087-94.

9. Spillane AJ, A'Hern R, Judson IR, Fisher C, Thomas JM. Synovial sarcoma: a clinicopathologic, staging, and prognostic assessment. J Clin Oncol. 2000;18:3794-803.

10. Trassard M, Le Doussal V, Hacene K, Terrier P, Ranchère D, Guillou L, et al. Prognostic factors in localized primary synovial sarcoma: a multicenter study of 128 adult patients. J Clin Oncol. 2001;19:525-34.

11. Guillou L, Benhattar J, Bonichon F, Gallagher G, Terrier P, Stauffer E, et al. Histologic grade, but not SYT-SSX fusion type, is an important prognostic factor in patients with synovial sarcoma: a multicenter, retrospective analysis. J Clin Oncol. 2004;22:4040-50. 
12. Ferrari A, Gronchi A, Casanova M, Meazza C, Gandola L, Collini P, et al. Synovial sarcoma: a retrospective analysis of 271 patients of all ages treated at a single institution. Cancer. 2004;101:627-34.

13. Ladanyi M, Antonescu CR, Leung DH, Woodruff JM, Kawai A, Healey JH, et al. Impact of SYT-SSX fusion type on the clinical behavior of synovial sarcoma: a multi-institutional retrospective study of 243 patients. Cancer Res. 2002;62:135-40.

14. Rosen G, Forscher C, Lowenbraun S, Eilber F, Eckardt J, Holmes C, et al. Synovial sarcoma: uniform response of metastases to high dose ifosfamide. Cancer. 1994;73:2506-11.

15. Karavasilis V, Seddon BM, Ashley S, Al-Muderis O, Fisher C, Judson I. Significant clinical benefit of first-line palliative chemotherapy in advanced soft-tissue sarcoma: retrospective analysis and identification of prognostic factors in 488 patients. Cancer. 2008;112:1585-91.

16. Eilber FC, Brennan MF, Eilber FR, Eckardt JJ, Grobmyer SR, Riedel E, et al. Chemotherapy is associated with improved survival in adult patients with primary extremity synovial sarcoma. Ann Surg. 2007;246:105-13.

17. Francis $P$, Namlos HM, Muller $C$, Edén P, Fernebro J, Berner JM, et al. Diagnostic and prognostic gene expression signatures in 177 soft tissue sarcomas: hypoxia-induced transcription profile signifies metastatic potential. BMC Genomics. 2007;8:73.

18. Nagayama S, Katagiri T, Tsunoda T. Genome-wide analysis of gene expression in synovial sarcomas using a cDNA microarray. Cancer Res. 2002:62(20):5859-66.

19. Kim RH, Li BD, Chu QD. The role of chemokine receptor CXCR4 in the biologic behavior of human soft tissue sarcoma. Sarcoma. 2011;2011:593708.

20. Oda Y, Tateishi N, Matono H, Matsuura S, Yamamaoto H, Tamiya S, et al. Chemokine receptor CXCR4 expression is correlated with VEGF expression and poor survival in soft-tissue sarcoma. Int J Cancer. 2009;124(8):1852-9.

21. Tornkvist M, Natalishvili N, Xie Y, Girnita A, D'Arcy P, Brodin B, et al. Differential roles of SS18-SSX fusion gene and insulin-like growth factor-1 receptor in synovial sarcoma cell growth. Biochem Biophys Res Commun. 2008:368:793-800.

22. Xie $Y$, Skytting B, Nilsson G, Brodin B, Larsson O. Expression of insulin-like growth factor-1 receptor in synovial sarcoma: association with an aggressive phenotype. Cancer Res. 1999;59:3588-91.

23. Ferrari S, Zanella L, Alberghini M, Palmerini E, Staals E, Bacchini P. Prognostic significance of immunohistochemical expression of ezrin in non-metastatic high-grade osteosarcoma. Pediatr Blood Cancer. 2008;50(4):752-6.

24. Lu YJ, Birdsall S, Summersgill B, Smedley D, Osin P, Fisher C, et al. Dual colour fluorescence in situ hybridization to paraffin-embedded samples to deduce the presence of the $\operatorname{der}(X) t(X ; 18)(p 11.2 ; q 11.2)$ and involvement of either the SSX1 or SSX2 gene: a diagnostic and prognostic aid for synovial sarcoma. J Pathol. 1999:187:490-6.

25. Sun Y, Gao D, Liu Y, Huang J, Lessnick S, Tanaka S. IGF2 is critical for tumorigenesis by synovial sarcoma oncoprotein SYT-SSX1. Oncogene. 2006;25(7):1042-52.

26. Enneking WF, Spanier SS, Goodman MA. Current concepts review. The surgical staging of musculoskeletal sarcoma. J Bone Joint Surg. 1980;62-A:1027-30.

27. Stanelle EJ, Christison-Lagay ER, Wolden SL, Meyers PA, La Quaglia MP. Pulmonary metastasectomy in pediatric/adolescent patients with synovial sarcoma: an institutional review. Pediatr Surg. 2013;48(4):757-63.

28. Rikhof B, de Jong S, Suurmeijer AJ, Meijer C, van der Graaf WT. The insulin-like growth factor system and sarcomas. J Pathol. 2009;217(4):469-82.

29. De Bruijn DR, Allander SV, Van Dijk AH, Willemse MP, Thijssen J, van Groningen $J$ J, et al. The synovial-sarcoma associated SS18-SSX2 fusion protein induces epigenetic gene (de)regulation. Cancer Res. 2006;66:9474-82.

30. Allander SV, Illei PB, Chen Y, Antonescu CR, Bittner M, Ladanyi M, et al. Expression profiling of synovial sarcoma by CDNA microarrays: association of ERBB2, IGFBP2, and ELF3 with epithelial differentiation. Am J Pathol. 2002;161(5):1587-95.

31. Friedrichs $N$, Küchler J, Endl E, Koch A, Czerwitzki J, Wurst P, et al. Insulin-like growth factor-1 receptor acts as a growth regulator in synovial sarcoma. J Pathol. 2008;216(4):428-39.

32. Sarfstein R, Pasmanik-Chor M, Yeheskel A, Edry L, Shomron N, Warman N, et al. Insulin-like growth factor-I receptor (IGF-IR) translocates to nucleus and autoregulates IGF-IR gene expression in breast cancer cells. J Biol Chem. 2012;287(4):2766-76

33. Gold KA, Kim ES, Liu D, Yuan P, Behrens C, Solis LM, et al. Prediction of survival in resected non-small cell lung cancer using a protein-expression based risk model: Implications for personalized chemoprevention and therapy. Clin Cancer Res. 2014;20(7):1946-54
34. Asmane I, Watkin E, Alberti L, Duc A, Marec-Berard P, Ray-Coquard I, et al. Insulin-like growth factor type 1 receptor (IGF-1R) exclusive nuclear staining: a predictive biomarker for IGF-1R monoclonal antibody (Ab) therapy in sarcomas. Eur J Cancer. 2012;48(16):3027-35.

35. Domanska UM, Kruizinga RC, Nagengast WB, Timmer-Bosscha H, Huls G, de Vries EG, et al. A review on CXCR4/CXCL12 axis in oncology: no place to hide. Eur J Cancer. 2013;49(1):219-30.

36. Scala S, Ottaiano A, Ascierto PA, Cavalli M, Simeone E, Giuliano P, et al. Expression of CXCR4 predicts poor prognosis in patients with malignant melanoma. Clin Cancer Res. 2005;11:1835-41.

37. Yopp AC, Shia J, Butte JM, Allen PJ, Fong Y, Jarnagin WR, et al. CXCR4 predicts patients outcome and recurrence patters after hepatic resection for colorectal liver metastases. Ann Surg Oncol. 2012;19 Suppl 3:S339-46.

38. Bachet JB, Maréchal R, Demetter P, Bonnetain F, Couvelard A, Svrcek M, et al. Contribution of CXCR4 and SMAD4 in predicting disease progression pattern and benefit from adjuvant chemotherapy in resected pancreatic adenocarcinoma. Ann Oncol. 2012;23(9):2327-35

39. Fanelli MF, Chinen LT, Begnami MD, Costa Jr WL, Fregnami JH, Soares FA, et al. The influence of transforming growth factor-a, cyclooxygenase-2, matrix metalloproteinase (MMP)-7, MMP-9 and CXCR4 proteins involved in epithelial-mesenchymal transition on overall survival of patients with gastric cancer. Histopathology. 2012;61(2):153-6.

40. D'Alterio C, Portella L, Ottaiano A, Rizzo M, Carteni G, Pignata S, et al. High CXCR4 expression correlates with sunitinib poor response in metastatic renal cancer. Curr Cancer Drug Targets. 2012;12(6):693-702.

41. Orimo A, Gupta PB, Sgroi DC, Arenzana-Seisdedos F, Delaunay T, Naeem R, et al. Stromal fibroblasts present in invasive human breast carcinomas promote tumor growth and angiogenesis through elevated SDF-1/CXCL12 secretion. Cell. 2005;121:335-48.

42. Duda DG, Kozin SV, Kirkpatrick ND, Xu L, Fukumura D, Jain RK. CXCL12 (SDF1-a) -CXCR4/CXCR7 pathway inhibition: an emerging sensitizer for anticancer therapies? Clin Cancer Res. 2011;17:2074-80.

43. Weng WH, Ahlén J, Aström K, Lui WO, Larsson C. Prognostic Impact of Immunohistochemical expression of ezrin in highly malignant soft tissue sarcoma. Br J Cancer. 1999:80:1809-14.

44. Skytting BT, Bauer HC, Perfekt R, Nilsson G, Larsson O. Ki-67 is strongly prognostic in synovial sarcoma: analysis based on 86 patients from the Scandinavian Sarcoma group register. Clin Cancer Res. 2005;11:6198-204.

45. Schneider-Stock R, Onnasch D, Haeckel C, Mellin W, Franke DS, Roessner A. Prognostic significance of p53 gene mutations and p53 protein expression in synovial sarcomas. Virchows Arch. 1999:435:407-12.

46. Lagarde P, Przybyl J, Brulard C, Pérot G, Pierron G, Delattre O, et al. Chromosome instability accounts for reverse metastatic outcomes of pediatric and adult synovial sarcomas. J Clin Oncol. 2013;31:608-15.

\section{Submit your next manuscript to BioMed Central and take full advantage of:}

- Convenient online submission

- Thorough peer review

- No space constraints or color figure charges

- Immediate publication on acceptance

- Inclusion in PubMed, CAS, Scopus and Google Scholar

- Research which is freely available for redistribution 